\title{
HOTEL HIBURAN DI TEPI PANTAI
}

\author{
Andrew Tjahyana ${ }^{1)}$, Priscilla Epifania ${ }^{2)}$ \\ ${ }^{1)}$ Program Studi S1 Arsitektur, Fakultas Teknik, Universitas Tarumanagara, andrewwyyy6@gmail.com \\ 2) Program Studi S1 Arsitektur, Fakultas Teknik, Universitas Tarumanagara, priscillae@ft.untar.ac.id
}

\begin{abstract}
Abstrak
Kawasan Pantai Indah Kapuk merupakan kawasan pemukiman yang memiliki daya dukung fasilitas yang cukup memadai. Pusat perbelanjaan, rumah sakit, perkantoran, apartemen, hotel, pendidikan, pusat kebugaran, pasar tradisional hingga modern, dan pusat hiburan seperti restoran dan kafe merupakan fasilitas yang dimiliki oleh Pantai Indah Kapuk. Dengan bertambahnya kepopuleran kawasan Pantai Indah Kapuk, bertambah pula jumlah pengunjung baik wisatawan asing serta wisatawan lokal. Berangkat dari potensi tersebut, maka dirancanglah sebuah proyek hotel hiburan yang terletak pada kawasan Pantai Indah Kapuk 2. Dengan lokasi tapak yang memiliki perbatasan dengan laut, diharapkan sebuah fasilitas hotel yang menekankan pada suatu aktifitas yang bersentuhan langsung dengan alam dapat dinikmati dan memberikan dampak yang baik terhadap wisatawan yang mengharapkan untuk mengalami sebuah pengalaman baru dalam fasilitas hiburan di kawasan ibukota Jakarta. Salah satu program unggulan dari fasilitas hotel hiburan tersebut adalah kasino. Dengan dibangunnya sebuah fasilitas kasino legal yang dapat dikelola dan diawasi oleh pemerintah, diharapkan sebuah terobosan baru dalam dunia wisata di ibukota dapat tercapai secara maksimal.
\end{abstract}

Kata kunci: Hotel hiburan, kasino legal, laut, Pantai Indah Kapuk 2

\begin{abstract}
Pantai Indah Kapuk area is a residential area that has sufficient carrying capacity. Shopping centers, hospitals, offices, apartments, hotels, education, fitness centers, traditional to modern markets, and entertainment centers such as restaurants and cafes are facilities owned by Pantai Indah Kapuk. With the increasing popularity of the Pantai Indah Kapuk area, the number of visitors to both foreign tourists and local tourists has also increased. Departing from this potential, an entertainment hotel project was designed which is located in Pantai Indah Kapuk 2. With the location of the site that has a border with the sea, it is expected that a hotel facility that emphasizes an activity that has direct contact with nature can have a good impact towards tourists who expect to experience a new experience in entertainment facilities in the capital city of Indonesia. One of the excellent programs of the entertainment hotel facilities is the casino. With the construction of a legal casino facility that can be managed and monitored by the government, it is hoped that a new breakthrough in the tourism sector especially in the capital city of Indonesia can be achieved optimally.
\end{abstract}

Keywords Entertainment hotel, legal casino, Pantai Indah Kapuk 2, sea

\section{PENDAHULUAN}

Salah satu hasrat yang diinginkan manusia adalah untuk bersantai menikmati hasil kerja keras dari rutinitasnya. Rekreasi atau wisata adalah jawaban dari persoalan ini. Gaya hidup dan kedekatan dengan alam adalah dua hal yang perlu diperhatikan lebih untuk menciptakan suatu 
destinasi wisata yang akan menarik minat warga perkotaan. Aktifitas hiburan yang memiliki karakteristik kuat dan dampak yang besar salah satunya adalah kasino. Kasino adalah permainan yang mempertaruhkan keberuntungan, memacu adrenalin dan melepas penat dari kesibukan sehari-hari. Kecintaan warga Indonesia untuk berjudi tidak dapat dibendung. Menurut hasil analisis Tim Craighead dan Brian C. Miller, Bloomberg tercatat pada tahun 2014, jumlah pelancong asal Indonesia yang mengunjungi pusat perjudian di negara tetangga, Singapura sebesar 234.389 orang atau sekitar 17, $19 \%$. Hal ini membuktikan minat dan potensial pembangunan kasino di Indonesia. Dari program kasino ini, muncullah program perhotelan yang menjadi program utama dari proyek ini. Konsep hotel yang mengutamakan kedekatan manusia dengan alam, akan menjadi daya tarik utama wisatawan. Suatu destinasi wisata perhotelan dengan fasilitas yang menunjang diharapkan dapat memberikan pengalaman yang berkesan bagi para wisatawan.

\section{METODE}

Metode perancangan yang digunakan berupa pendekatan deduktif melalui literature buku dan media elektronik dalam mengumpulkan data. Selain itu survey lapangan dilakukan pada lokasi pembangunan tapak (Pantai Indah Kapuk 2) dan lokasi terbangun Pantai Indah Kapuk 1. Metode selanjutnya adalah analisis kebutuhan ruang dan standar-standar pada bangunan hotel.

\section{DISKUSI DAN HASIL}

Tapak terpilih berada di pulau D reklamasi Pantai Indah Kapuk 2, Jakarta Utara dengan lebar jalan utama berkisar 15 meter dan jalan sekunder berkisar 10 meter. Memiliki spesifikasi berupa luas tapak 22.042 m2, KDB 50\%, KLB 3, dan KB 20. Proyek hotel hiburan di tepi pantai memiliki karakteristik jalan sebagai berikut; besar jalan utama yaitu 15 meter dan jalan sekunder (tapak) sebesar minimal 10 meter. Kondisi tapak terbangun pada saat ini masih berupa lahan kosong yang memiliki peruntukkan sebagai zona perdagangan dan perkantoran dengan ketinggan sedang.

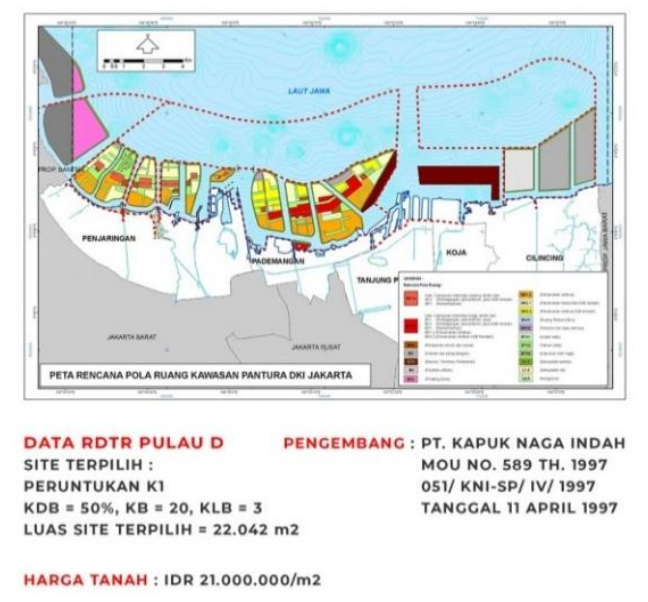

Gambar 1. Data Tapak 1

Sumber: Olahan pribadi, 2018

Kasino sebagai program pendukung utama pada hotel hiburan di tepi pantai ini menjadi faktor utama dalam penetapan konsep proyek terbangun. Koin merupakan salah satu objek yang tidak dapat dipisahkan dari permainan kasino, sehingga bentuk lingkaran menjadi bentuk yang mendominasi pada massa-massa bangunan. Sehingga konsep tumpukan koin menjadi konsep dalam proses desain bangunan hotel hiburan di tepi pantai. 


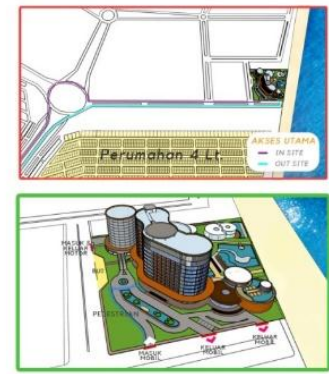

Gambar 2. Data Tapak 2

Sumber: Olahan pribadi,2018

Tema yang dikeluarkan dari hasil analisa tapak adalah kontemporer tropikal. dikarenakan lokasi tapak yang berada di tepi laut dan memiliki pantai pribadi sehingga aktifitas alam dapat ditonjolkan di dalam program pada tapak. Area pusat tapak dibuka ke arah laut sehingga tercipta sebuah aktifitas publik yang memiliki pemandangan yang bersentuhan dengan laut. Massa bangunan diletakkan dengan bentuk mengelilingi area terbuka publik yang menghadap ke arah laut. Letak sirkulasi kendaraan di dalam tapak diletakkan berdekatan dengan jalan utama sehingga memiliki akses yang mudah dicapai.

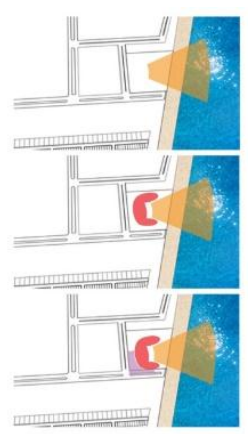

Gambar 3. Analisa Tapak \& Sirkulasi

Sumber: Olahan pribadi, 2018

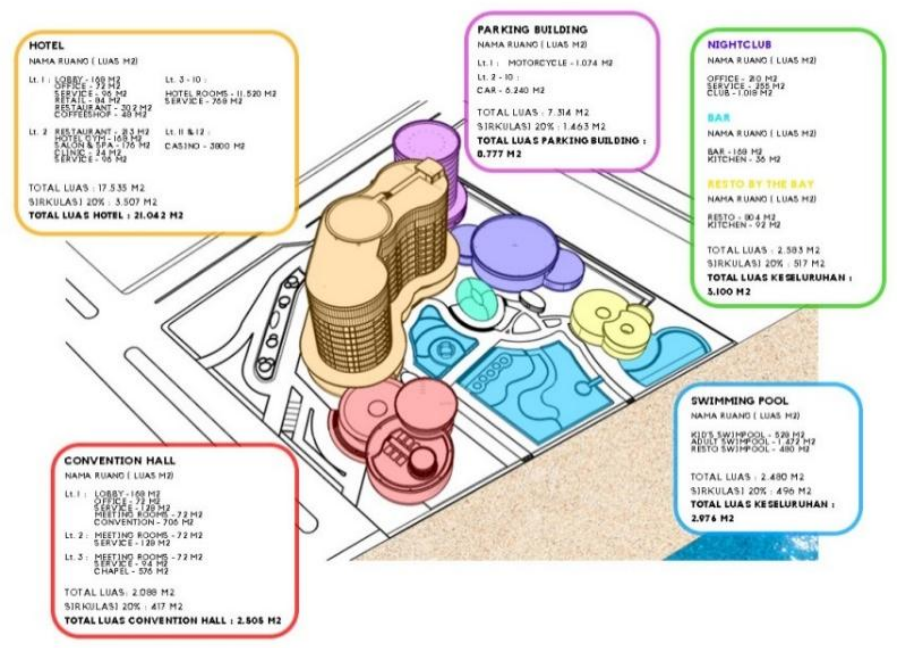

Gambar 4. Program Ruang

Sumber: Olahan pribadi, 2018

Massa yang terdapat pada tapak adalah hotel, gedung parkir, convention hall, nightclub, bar, dan resto by the bay. Pada massa hotel, lantai satu dan dua merupakan ruang fasilitas hotel seperti lobby, restoran, kantor hotel, kantor kasino, entrance menuju kasino, gym, health 
care \& spa. Lantai tiga hingga lantai sepuluh merupakan kamar hotel. Lantai sebelas dan dua belas merupakan area kasino yang dengan sengaja diletakkan pada bagian teratas pada massa hotel dikarenakan permasalahan keamanan. Pada atap hotel terdapat landasan helikopter sebagai fasilitas bagi pengunjung kasino.

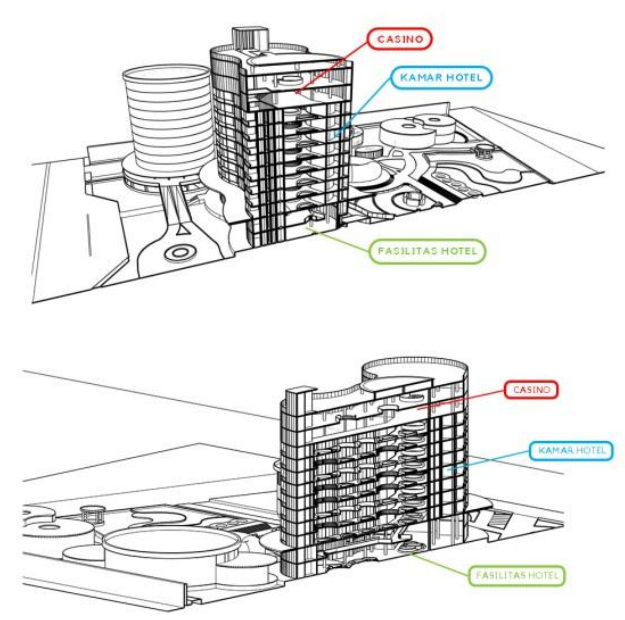

Gambar 5. Potongan Perspektif Sumber: Olahan pribadi, 2018

Bahan material yang mendominasi pada massa-massa bangunan adalah kayu pada bagian interior bangunan, kaca mendominasi bagian fasad bangunan, marmer digunakan pada lantai lobi hotel dan ruang konvensi, dan bata pada bagian outdoor
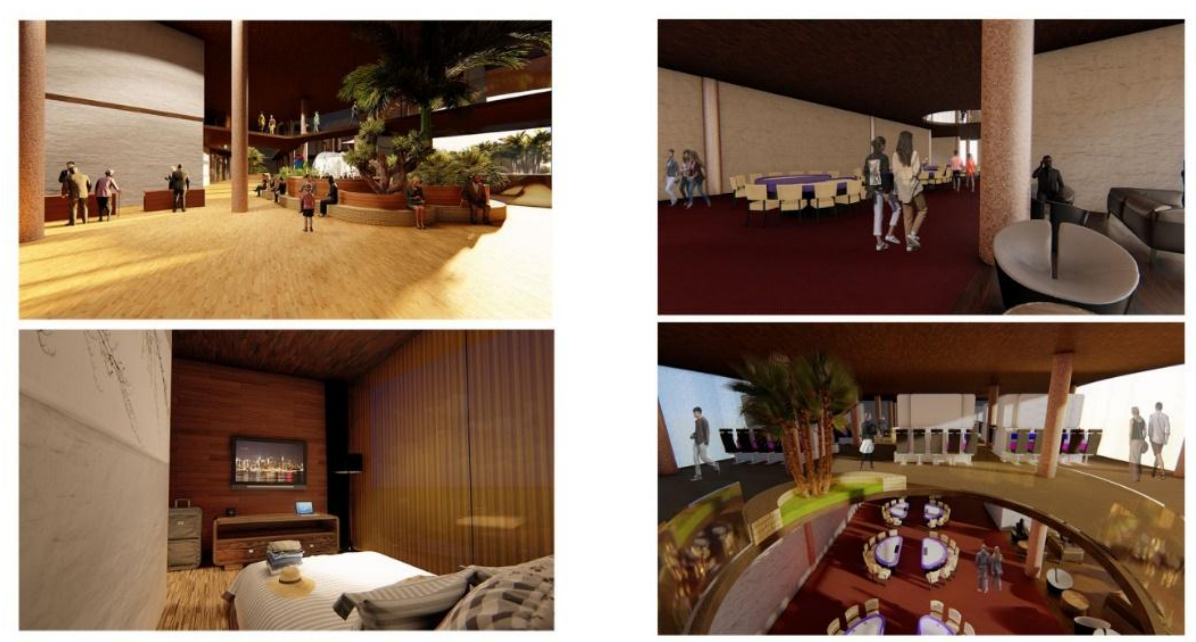

Gambar 6. Perspektif Indoor 1

Sumber: Olahan pribadi, 2018 


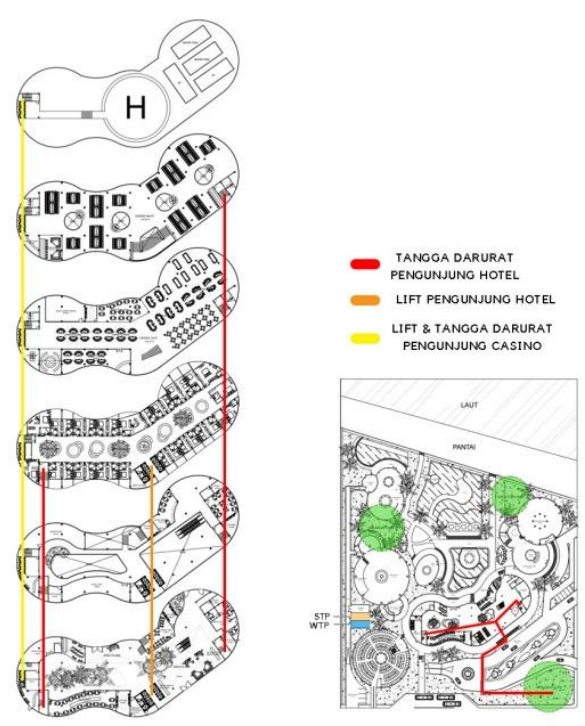

Gambar 7. Sirkulasi Evakuasi

Sumber: Olahan pribadi, 2018

Pada bagian keamanan terdapat 3 ruang evakuasi yakni bagi pengunjung hotel, pengunjung bagian massa bangunan hiburan, dan pengunjung konvensi. Pada massa hotel, terdapat 3 tangga darurat. Dua tangga darurat yang berada di ujung masing-masing massa yang diperuntukkan untuk tamu hotel, dan satu yang disediakan khusus bagi pengunjung kasino.

\section{KESIMPULAN DAN SARAN}

Pembagian zonasi massa terjadi dikarenakan beberapa alasan. Massa hotel terletak pada bagian depan tapak berdekatan dengan jalan utama dikarenakan program utama yaitu hotel memiliki akses yang mudah untuk dicapai oleh pengunjung. Massa gedung pertemuan terletak pada bagian samping tapak dan berdekatan juga dengan jalan utama. Terdapat sirkulasi jalan mobil yang melewati area gedung pertemuan sehingga dapat memudahkan pengunjung gedung pertemuan untuk mencapai gedung pertemuan tersebut. Gedung parkir terdapat pada bagian ujung muka tapak agar memudahkan sirkulasi mobil dan motor yang hendak memarkirkan kendaraannya untuk masuk kedalam massa tapak. Nightclub berada dekat dengan gedung parkir dengan tujuan untuk memudahkan pengunjung mencapai massa tersebut. Terutama dikarenakan kemudahan dan keamanan pengunjung yang banyak dikunjungi pada malam hari. Restoran diletakkan dekat dengan pantai sehingga memiliki pemandangan langsung ke arah laut. Bar hotel juga diletakkan dekat dengan fasilitas kolam renang serta memiliki pemandangan langsung ke arah laut. Kualitas ruang yang ingin dicapai pada bangunan ini adalah kualitas ruang yang berkualitas, nyaman, terbuka, dan memiliki nuansa tropis. Hal ini dicapai dengan plafond yang tinggi, material kaca dan kayu, serta tanaman tropis yang terletak pada setiap sudut bangunan.

\section{REFERENSI}

https://www.researchgate.net/publication/298952575_THE_VALUE_OF_ARCHITECTURE_TO_T OURISM, diakses 16 Juli 2018

https://issuu.com/nahalfathi/docs/architectural_icons, diakses 3 Agustus 2018

http://www.iaacblog.com/programs/architectures-role-in-tourism-and-city-branding_/, diakses 6 Agustus 2018

https://www.researchgate.net/publication/298952575_THE_VALUE_OF_ARCHITECTURE_TO_T

OURISM, diakses 6 Agustus 2018 
https://issuu.com/nahalfathi/docs/architectural icons, diakses 16 Agustus 2018 [6]. http://fgb.itb.ac.id/wp-content/uploads/2016/06/2016-04-22-Petrus-Natalivan.pdf, diakses 16 Agustus 2018

http://www.iaacblog.com/programs/architectures-role-in-tourism-and-city-branding_/, diakses 16 Agustus 2018

https://www.malaysiasite.nl/gentingcasinoeng.htm, diakses 17 Agustus 2018

http://cyberlaw-judionline.blogspot.com/2014/06/bunyi-pasal-303-kuhp.html, diakses 17 Agustus 2018

https://www.arsitag.com/article/standar-hotel-bintang-5, diakses 23 Agustus 2018 http://www.theresidencehotel.com/banquets/convention-centre, diakses 27 Agustus 2018 A. Rutes, Walter. (1985). Hotel Planning and Design. New York, USA. Spect, Jan. (2014). Architectural Tourism. Germany: Springer Gabler. 